\title{
A internet em McLuhan, Baudrillard e Habermas
}

\section{The internet in the works of McLuhan, Baudrillard and Habermas}

\author{
José Carlos Moreno* \\ * ISCTE - Instituto Universitário de Lisboa
}

\section{Resumo}

Habermas, Baudrillard e McLuhan representam três das principais linhas científicas de análise global do fenómeno dos media e da sua interacção com a sociedade. No entanto, qualquer dessas análises é anterior à emergência da internet como meio massivo de distribuição de informação, com as manifestações que conhecemos hoje. 0 objectivo deste trabalho é analisar de que forma a internet actual se inscreve, ou não, nas teses de cada um desses autores, através do mapeamento das suas teses e das dos seus sucessores; e perceber se as características da internet obrigaram à revisão das teses desses autores, pelos próprios ou pelos seus sucessores. Examinaremos, por ordem cronológica, as teses de Marshal McLuhan, Jean Braudrillard e Jürgen Habermas, confrontaremos as teorias de cada um deles com os desafios que hoje lhes coloca a internet e, por fim, procuraremos tirar conclusões sobre se a manifestação social actual da internet obrigou ou não a uma revisão das teses de cada um.

Palavras-chave: Marshal MLuhan, Jean Baudrillard, Jürgen Habermas, internet, media

\begin{abstract}
Habermas, Baudrillard and McLuhan represent three of the main scientific approaches to the phenomenon of the interaction between media and society. However all those approaches are prior to the internet as a massive medium for the distribution of information, like we experience it today. The purpose of this article is to analyze if the internet as we know it today can in any way be inscribed within the thesises of each of those authors, mapped out though their own writings or the writings of their successors; and to figure out if the modern development of the internet forced a revision of those author's thesis, either by themselves or by their successors. We will examine, in chronological order, the thesis of Marshal McLuhan, Jean Baudrillard and Jürgen Habermas, we will confront the theories of those authors with the challenges that the internet poses them and we will conclude by checking if the internet has forced a revision of their main theoretical thesises.
\end{abstract}

Keywords: Marshal McLuhan, Jean Baudrillard, Jürgen Habermas, internet, media

\section{Introdução}

Jürgen Habermas, Jean Baudrillard e Marshal McLuhan são três dos mais importantes teóricos da comunicação contemporâneos. Todos eles têm quadros de referência analítica abrangentes que permitem enquadrar a maior parte das facetas da comunicação e das suas implicações e manifestações sociais. Não abordam apenas uma faceta da comunicação. Construíram - qualquer deles - um conjunto complexo de

Copyright (C) 2013 (José Carlos Moreno). Licensed under the Creative Commons Attribution Noncommercial No Derivatives (by-nc-nd). Available at http://obs.obercom.pt. 
conceitos inter-relacionados que permitem enquadrar a maior parte das manifestações concretas das formas de comunicação em sociedade.

Tanto Habermas como Baudrillard e McLuhan construíram as suas teses complexas antes da criação, desenvolvimento e generalização world wide web. Talvez seja por isso pertinente perguntar: 1) Como é que a comunicação em rede que hoje conhecemos se inscreve no complexo teórico de Habermas, Baudrillard e McLuhan? 2) Como é que os seus seguidores combinam as suas teses com os mais recentes desenvolvimentos observados? 3) Como é que os próprios reagem ou reagiram à internet, se é que existe registo histórico dessa reacção?

É isso que pretendemos fazer neste trabalho, o qual será, por isso mesmo, de uma dupla natureza. Por um lado, será sobretudo teórico, identificando as teses principais dos três autores e a forma como a moderna comunicação em rede (Castells, 2009, p.8), se pode ou não inscrever nelas, seja segundo os próprios seja segundo os seus seguidores e continuadores. Mas, por outro lado, será também pontualmente histórico quando tentar recuperar registos de reacções pessoais de Habermas, Baudrillard ou McLuhan às novas tecnologias de comunicação, à internet e/ou a eventos despoletados por ambas.

A hipótese subjacente a esta análise é de que a magnitude das transformações operadas pela comunicação em rede desafia até as mais bem estabelecidas e sedimentadas formulações teóricas globais sobre comunicação. E que isso se apresenta como mais um argumento para sustentar a tese de que a emergência da comunicação em rede através da internet é em si mesma um elemento desregulador com consequências massivas a todos os níveis da organização social, económica e política.

\section{Mashal McLuhan: a internet vista ao retrovisor}

Marshal McLuhan nasceu em 1911 e publicou obras sobre teoria de comunicação durante um período de mais de 40 anos, até à sua morte em 1980. Os seus trabalhos mais importantes - "The Mechanical Bride", "The Gutenberg Galaxy" e "Understanding Media" (Marchessault, 2005, p. xv-xvi) - datam de 1951, 1962 e 1964, respectivamente. Por essa altura, McLuhan tinha já sedimentado o essencial das suas ideias sobre a evolução dos media, bebendo sobretudo dos ensinamentos de Harold Innis e Eric Havelock.

As teses de McLhuan sobre os media são holísticas - procuram explicar todos os fenómenos mediáticos desde a primeira produção comunicativa registada entre seres humanos - e são determinísticas, no sentido em que fazem depender o fenómeno em estudo de um só factor dominante - neste caso a tecnologia. Por isso, as teses de McLuhan não só traçam uma linha de causalidade que nos trouxe do passado até ao presente, como permitem projectar essa linha no futuro. Ou seja, como todas as teses determinísticas, o futuro será necessariamente a continuação do presente segundo a linha traçada desde o passado. Por isso, 
embora Marshal McLuhan não tivesse conhecido a internet e tivesse morrido antes da criação da world wide web, é possível analisar as suas teses principais à luz dos desenvolvimentos actuais das tecnologias de comunicação e informação e dos usos sociais que delas são feitos, quer relendo as suas obras mais importantes, quer usando como "retrovisor" teórico a leitura que destes temas é feita pelos seus continuadores e seguidores.

Como foi salientado por vários autores por altura do centenário do seu nascimento, em 2011, embora Marshal McLuhan tenha falecido no limiar da "revolução do computador pessoal, que havia de mudar o nosso mundo" (Levinson, 1999, p.16), muitas das suas teses sobre comunicação parecem talhadas para explicar o mundo de hoje. Kevin Kelly, por exemplo, é citado na contracapa do livro de Paul Levinson afirmando que "Toda a gente achava que McLuhan estava a falar da televisão, mas na verdade aquilo de que ele estava a falar era da internet" (Levinson, 1999, contracapa). Sendo uma formulação analítica de muito grande envergadura, a teoria dos media e da comunicação de Marshal McLuhan oferece um vasto campo de conceitos nos quais podemos pegar para os cotejar com o que é hoje a realidade da comunicação na era da internet. E o primeiro desses conceitos é o já famoso "the media is the message" ("o meio é a mensagem"). Para Marshal McLuhan, o "meio é a mensagem" não só porque as características do meio - "quente" ou "frio" - tendem a determinar o tipo de envolvimento que os destinatários estabelecem com ele; mas - sobretudo - porque em McLuhan o "meio" é uma extensão do aparelho sensorial e do sistema nervoso central do ser humano. E é por essa razão que nos condiciona como indivíduos e como sociedade. Para McLuhan, é esse efeito que importa, muito mais que qualquer efeito que possamos atribuir à mensagem que o meio veicula. Obviamente, considerando a primeira das duas acepções acima, uma emissão de televisão, um trecho de rádio ou um texto escrito terão as mesmas características quando vistos, ouvidos ou lidos num monitor de um computador ligado à internet do que teriam no aparelho original para o qual foram concebidos. O que verdadeiramente existe aqui de novo - e que se liga com o que McLuhan deixou subentendido nos seus escritos - é o computador visto como uma extensão do sistema nervoso central, não só coordenando as extensões sensoriais que são a nossa utilização dos diversos media como, ainda mais importante, introduzindo o conceito de extensão de consciência (McLuhan, 1964, p.73).

Devemos perceber, comparando as cronologias de desenvolvimento das tecnologias de comunicação e das teorias de McLuhan sobre os media, que o académico canadiano nunca conheceu a internet, mas viveu a tempo de conhecer e perceber as implicações que o computador poderia ter nos media da época. Aliás, conjugando os media como extensões da nossa sensibilidade e o computador como extensão do nosso sistema nervoso central, Derrick de Kerkhove, num dos muito eventos evocativos realizados em 2011, citou o próprio McLuhan em "Understanding Media" (1962) com chamadas de atenção numéricas, para ilustrar o 
carácter premonitório de vários pontos da sua análise face à realidade dos nossos dias: "The next medium, whatever it is (1) it may be the extension of consciousness, (2) will include television as it's content, not as its environment, and (3) will transform television into an art form. A computer as (4) a research and communication instrument could (5) enhance retrieval, (6) obsolesce mass library organization, (7) retrieve individual's encyclopedic function and flip into (8) a private line to (9) speedly tailored data of (10) a saleable kind." (Marshal McLuhan, citado por Derrick de Kerkhove, em Ciastellardi, 2011, p.10). Num parágrafo como este temos a conjugação dos vários media como extensões do sistema sensorial humano e do computador como extensão do sistema nervoso central actuando num modelo global de comunicação conjugável com as formas como a comunicação se materializa na prática hoje em dia.

Um segundo conceito central nas teses de McLuhan é o conceito de aldeia global. Recorde-se que, para McLuhan, o passado tribal do ser humano era vivido em "aldeias" nas quais a comunicação era oral e todos os assuntos da aldeia interessavam a todos os elementos da tribo. Antes da invenção da imprensa e da passagem para um estado de comunicação literária, predominantemente escrita, em que os campos de intervenção se especializaram. Mas, nos tempos modernos, citando o próprio McLuhan, "the electromagnetic discoveries have recreated the simultaneous 'field' in all human affairs so that the human family now exists under conditions of a 'global village'. We live in a single constricted space resonant with tribal drums" (McLuhan, 1962, p.31). Ou seja, os novos media electrónicos não só mudaram o paradigma de comunicação (de escrito para oral) como uniram todo o planeta numa "aldeia" única. Ora, se isso era já aparente no tempo de McLuhan, sobretudo com a rádio e a televisão (descendentes directos do telégrafo, que foi o primeiro dos media eléctricos) tornou-se ainda mais manifesto nos tempos que correm, com o alcance global da internet e com o facto de ela permitir combinar o efeito unificador dos eventos de carácter global com a interacção com todos os membros da "tribo electrónica" em simultâneo e no contexto desse evento. Aliás, há autores que levam ainda mais longe esta leitura de McLuhan (como Walter Ong e Eric Havelock, por exemplo), que derivam da oposição entre culturas orais e culturas escritas a hipótese de uma maior capacidade de empatia dos seres humanos que tenderia a evoluir para uma consciência global à escala humana (Rifkin, 2009, p.204-212). Aliás, o próprio McLuhan o formula como pergunta em "Understading Media": "(...) might not our current translation of our entire lives into the spiritual form of information seem to make of the entire globe, and of the human family, a single consciousness?" (McLuhan, 1964, p. 73). Obviamente, estas "extensões" do pensamento de Marshal McLuhan - que terminam frequentemente em utopias ou distopias - são decorrências lógicas de uma abordagem simultaneamente holística e determinística. De qualquer forma, a maneira como socialmente usamos a comunicação na era da internet parece concluir e confirmar esta abordagem de McLuhan relativa à "aldeia global". 
Como já aflorámos acima, Marshal McLuhan também dividiu os media do seu tempo em "cool" ou "hot". Para McLuhan eram "cool" ou "frios" os media que faziam a extensão de um dos sentidos humanos em "alta definição" e portanto exigiam pouco envolvimento por parte do destinatário; e eram "hot" ou "quentes" os media que faziam a mesma extensão de um dos sentidos humanos, mas em "baixa" definição, obrigando por isso a um maior envolvimento por parte do destinatário (McLuhan, 1964, p.30-31). Ou seja, os media "cool" tendem a gerar uma maior participação da audiência que os media "hot". Por outro lado, Marshal nMcLuhan também traçou uma história dos alfabetos humanos desde os ideográficos aos fonéticos, identificando nesse processo um aumento de "temperatura" do media. Ou seja, as escritas ideográficas eram um media "frio" porque exigiam grande interpretação e desconstrução por parte do destinatário e as escritas alfabéticas, pelo contrário, eram um media "quente" porque se impõem ao destinatário sem necessidade de serem completados pelo destinatário e portanto suscitando um menor grau de envolvimento (McLuhan, 1964, p.94-95).

Ora, Marshal McLuhan não chegou a conhecer a internet e portanto não podemos adivinhar se a teria considerado, de per se, um media frio ou quente (ou sequer um media, já agora). Até porque a própria internet evoluiu de ser inicialmente apenas um sustentáculo para informações veiculadas por texto escrito em forma electrónica para ser hoje uma plataforma onde se conjugam todos os media tradicionais: som, imagem em movimento, grafismos e texto escrito. Paul Levinson, por exemplo, considera que a comunicação online é, sob qualquer perspectiva, o meio mais interactivo da história e que a internet conjuga em si dois media "frios" - o telefone e a televisão - e um media quente - o livro/texto - aqui tornado mais "frio" pela sua natureza electrónica (Levinson, 1999, p.114). O resultado é um media que suscita um alto envolvimento, não só por essas suas características como também por permitir facilmente ligações entre conteúdos muito diversos em locais distantes. Para Neil Postman, pelo contrário, um computador ligado à internet é em tudo semelhante a uma televisão em termos de ligação com a audiência, suscitando portanto o mesmo tipo de consequências sociais alienadoras (Postman, 1992, pp.118-120). Para Derrick de Kerkhove, como já vimos acima, a internet, mais do que um media, é um "cérebro colectivo" com capacidade computacional inédita, conjugando milhões de processadores em todo o mundo e acesso ilimitado a gigantescos bancos de memória (De Kerckhove, 1997, p.54-55). É portanto muito mais do que apenas um media.

Ou seja, o que parece mais seguro concluir da conjugação destas perspectivas é que McLuhan percebeu, já no seu tempo, o potencial do computador, mas não poderia antecipar a forma como ele seria utilizado para tornar exponenciais as ligações entre diferentes media e, sobretudo, entre todos os indivíduos. Numa palavra, não poderia adivinhar a arquitectura em rede que o computador ligado à internet colocaria ao dispor dos utilizadores e que viria a influenciar a forma como estes combinam e recombinam a informação, 
incluindo a originária dos media tradicionais. E, como é evidente, não estamos aqui perante uma questão menor, mas sim perante a evolução da organização básica do tecido social do ponto de vista do fluxo de comunicação entre as suas diversas células. Ou seja, a visão futurista de McLuhan gerada pela sua crença no determinismo tecnológico falhou num ponto essencial: projectou uma evolução tecnológica correcta mas numa ligação tradicional entre os media e os consumidores de media, quando, na verdade, a internet evoluiu, até por razões subjectivas, para uma arquitectura em rede. 0 que significa que se aplica aqui o conceito de domesticação introduzido por Silverstone (2003): a tecnologia que tornou possível a internet foi apropriada pelos indivíduos e integrada nos seus fluxos de uma forma que não era necessariamente aquela que era imposta pela própria tecnologia.

Na esteira de McLuhan, Neil Postman foi o grande crítico daquilo que, nas suas teses e nas de McLuhan, era o caminho imposto pela evolução tecnológica à função social da informação. Primeiro com "Amusing ourselves to death" (2006), com uma crítica à influência do entretenimento televisivo na cultura e sociedade; e depois com "Informing ourselves to death", um conceito introduzido num discurso de 1990 e seguido no livro "Technopoly: The Surrender of our Culture to Technology" (1992), o qual afirma que a tecnologia multiplica exponencialmente a abundância de informação e com isso dilui as referências dos indivíduos e corta a ligação entre a informação e a sua função, instituindo o caos. Uma visão obviamente alarmista, mas não menos determinística que a de McLuhan. Pegando no conceito anterior de Silverstone, diríamos que a tecnologia - neste caso as tecnologias de informação que permitem aumentar exponencialmente a abundância de informação - ainda estão a ser domesticadas e apropriadas pelos usos específicos de cada contexto social, económico e outros.

\section{Jean Baudrillard: a grande alucinação colectiva}

Jean Baudrillard escreveu abundantemente entre 1968 e 2010. Tal como em McLuhan e Habermas, teses de Baudrillard sobre comunicação fazem parte - determinante - de uma visão geral da sociedade. Começou por teorizar sobre a comunicação como um complemento do modo de produção capitalista (a crítica da economia política do signo como complemento da crítica da economia política), mas progressivamente começou a tomar as suas reflexões como uma base para uma nova - e autónoma - teoria crítica da sociedade (Baudrillard, 1988, pp.3-4).

Segundo Baudrillard, "nós consumimos os produtos como produtos e consumimos o seu significado através da publicidade" (Baudrillard, 1988, p.10), o que significa que os objectos se constituem como um sistema dentro do domínio do consumo, o "sistema dos objectos" que serviu de título ao seu primeiro livro. Para ele, da moralidade puritana dominante nas sociedades tradicionais tínhamos passando a uma moralidade 
predominantemente hedonística nas sociedades modernas (Baudrillard, 1988, p.11). Sob a égide do consumo, os objectos adquirem personalidade própria e relacionam-se entre si e com o sujeito mediante uma linguagem complexa de signos e significados sociais. No âmbito dessas relações desenvolve-se um código de "standing", de reconhecimento de estatutos sociais (Baudrillard, 1988, p.17) que funciona como uma forma de socialização, a nova forma de socialização das sociedades modernas. É no entanto - uma tese que será central em Baudrillard - um código de falsas relações sociais, por detrás do qual as verdadeiras estruturas de produção e correspondentes relações socias - da doutrina marxista permanecem ilegíveis (Baudrillard, 1988, p21).

Baudrillard identificou nos objectos uma lógica funcional do valor de uso, uma lógica económica do valor de troca, uma lógica diferencial do valor de signo e, sobretudo, uma lógica de troca simbólica (Habermas, 1988, p.57). Para este pensador francês, as teses anteriores tinham já abordado os objectos - em conjunto ou separadamente - nas três primeiras acepções - mas não na quarta, que para ele era a mais importante e subsumia as restantes. Instituíam-se portanto, três ordens sociais: a ordem da produção, a ordem do consumo e e ordem da significação (Baudrillard, 1988, p.103). A ordem da significação é aquela estruturação da sociedade onde se produzem os simulacros e simulações, o principal contributo teórico de Baudrillard para a história das teorias da comunicação.

Para Baudrillard, a imitação era o esquema de significação dominante na época clássica, da Renascença à Revolução Industrial; a produção era o esquema dominante na época industrial; e a simulação é o esquema de significação dominante no nosso tempo (Baudrillard, 1988, p.135). É por meio de simulacros e simulações que se estabelece uma espécie de hiper-realidade que não existe senão no "reino da simulação" e cuja função - mais que efeito - é precisamente ocultar a realidade (Baudrillard, 1998, p.146). Ou seja, a própria realidade é hiper-realista e vivemos todos numa espécie de alucinação colectiva. Para Baudrillard, podemos ver por todo o lado o mesmo "genesis de simulacra": a comutação inconsequente e insignificante entre o feio e o bonito na moda, entre a esquerda e a direita na política, entre verdadeiro e falso nos media e entre útil e inútil ao nível dos objectos (Baudriillard, 1998, p.128). Em todas essas manifestações, o que a hiper-realidade mostra não é algo diferente da realidade; é a própria ausência da realidade (Baudrillard, 1998, p.167-168). O próprio Baudrillard dá exemplos do universo comunicativo para explicar como a articulação de simulacros na hiper-realidade dos nossos dias oculta a própria realidade, nomeadamente a Disneylândia, onde os imaginários não são na verdade verdadeiros nem falsos (Baudrillad, 1998, p. 172) e o caso Watergate, que na verdade não é um escândalo mas sim uma dissimulação destinada a esconder algo (Baudrillard, 1998, p.173). Resta saber se a propagação destas simulações e simulacros com a distribuição de informação na idade da internet e na sociedade em rede na qual hoje vivemos serve para desmascarar ou para reforçar as simulações, e portanto para reforçar e amplificar a hiper-realidade de 
Baudrillard ou, pelo contrário, para desconstruir e denunciar essas simulações da realidade e atingir a verdade. $\mathrm{O}$ que, a acontecer, aconteceria portanto já num "mundo" diferente daquele que foi "pensado" por Baudrillard.

Segundo Baudrillard, até hoje houve duas grandes versões na análise dos media - uma optimista e outra pessimista - sendo que a primeira se divide em duas tonalidades: a primeira, tecnológica, é corporizada por Marshal McLuhan; a segunda, ideológica, dialéctica e progressista no sentido marxista, foi elaborada por vários autores, entre eles Hans Enzensberger, com o seu ensaio "Constituents od a Theory of Media" (1970. Foi em oposição a esta visão que Baudrillard escreveu o seu ensaio "Requiem pelos media" (1972), publicado como um capítulo do livro "Para uma Crítica da Economia Política do Signo" (1981). Ambos os ensaios fazem parte da antologia "The New Media Reader" citada na bibliografia.

Para Baudrillard os mass media "fabricam incomunicação, isto se aceitarmos que a definição de comunicação implica uma troca, como um espaço recíproco de discurso e resposta, e portanto também de responsabilidade" (Baudrillard, 1998, p207). Ou seja, os mass media fazem precisamente o contrário disso e, quando muito, encenam simulações de resposta perfeitamente integradas no processo de emissão e que em nada alteram a unilateralidade da comunicação.

Baudrillard identifica a evolução dos tipos de comunicação até ao mundo do digital que nos rodeia hoje em dia (Baudrillard, 1998, p.143), mas não especula sobre o efeito que os códigos binários poderão ter na computação e na internet. O que afirma é que a sobreabundância de informação que caracteriza o nosso tempo não reduz a incerteza. Pelo contrário, essa sobreabundância reforça a própria incerteza e o campo do jogo de sombras onde se manifestam os simulacros e simulações da hiper-realidade moderna (Baudrillard, 1998, 219-211). Os eventos são encenados em múltiplos ecrãs que não são já apenas o ecrã da televisão, mas sim os vários ecrãs da informação, "esfera da informação", como também the chama. No entanto, a simulação e a "ausência encenada" são as mesmas em todos eles (Baudrillard, 1998, pp.213214).

Mark Poster refere uma entrevista de Baudrillard na qual o teórico francês confessava que continuava a usar a máquina de escrever, com cujas letras impressas podia manter uma relação directa, pessoal e material. Com o ecrã, isso não era possível. Ou seja, o ecrã - como todos os ecrãs em Baudrillard, recordese - é um elemento de simulacro e simulação. Enquanto na máquina de escrever continua a haver uma relação sujeito-objecto, no ecrã do computador, segundo Baudrillard - interpretado por Poster - o sujeito tem que "entrar" no ecrã, tem que se diluir nele para interagir com o conteúdo que está "dentro" do ecrã (Poster, 2001, p.114). Esse é o poder sedutor que todos os ecrãs têm e que Baudrillard atribuía por igual aos ecrãs da televisão ou aos ecrãs dos computadores. 
Nessa entrevista, Baudrillard respondeu o seguinte sobre qual era, do seu ponto de vista, o potencial alcance das novas tecnologias:

"I don't know much about this subject. I haven't gone beyond the fax and the automatic answering machine. I have a very hard time getting down to work on the screen because all I see there is a text in the form of an image which I have a hard time entering. With my typewriter, the text is at a distance; it is visible and I can work with it. With the screen, it's different; one has to be inside; it is possible to play with it but only if one is on the other side, and immerses oneself in it. That scares me a little, and Cyberspace is not of great use to me personally." (Thibaut, 1996)

Mas, com a criação do conceito de simulação do real por meio dos media, Baudrillard de certa forma inaugura muito antes do tempo o debate e a teorização que hoje é abundante sobre os mundos de realidade virtual e dos universos virtuais paralelos. Mark Poster (Poster, 2001, p.133), cita o teórico francês: "A idade da simulação começa com a liquidação de todos os referentes. Pior: pela sua ressurreição num sistema de signos." Para Baudrillard, a simulação ameaçava - extinguia mesmo - a relação entre o verdadeiro e o falso. É verdade que Baudrillard, nos seus escritos mais recentes, sempre que usou o termo "realidade virtual" usou-o de uma forma indecifrável do conceito de "simulação". Ele não entende a passagem da simulação à realidade virtual como algo de diferente natureza, mas apenas como a intensificação de um efeito (Poster, 2001, p.135). O próprio Baudrillard, na entrevista já referida acima, afirma que a internet "irá sem dúvida explodir em todas as direç̧ões, porque é um meio em expansão e irá crescer em todos os domínios. Mas no final a questão essencial permanece igual, e isso é que é o mais importante." (Thibaut, 1996).

Ou seja, para Baudrillard, a expansão dos ecrãs para a internet é irrelevante porque o seu funcionamento fundamental como teatro das simulações da hiper-realidade é o mesmo. Dito de outra forma, os ecrãs que nos servem a internet são os mesmos que nos serviam e servem os mass media. $\mathrm{E}$ a sua natureza de construtores de uma hiper-realidade é a mesma (Nunes, 1995, p.2). A forma como através da internet podemos por exemplo, "viajar" para vários locais diferentes sem sair do mesmo lugar representa, para Baudrillard, a materialização mais evidente de uma presença que esconde, precisamente, a sua ausência (Nunes, 1995, p.4).

Segundo Mark Nunes, os comentários feitos por Baudrillard nos seus livros mais recentes sugerem que para ele a comunicação telemática é aliás, a consumação última dos objectivos da comunicação, o seu telos (Nunes, 1995, p.5). Levando a leitura de Baudrillard aos últimos limites, diríamos, com Nunes, que "a telemática promove a dissuasão do que já aconteceu: o fim do espaço através do ciberespaço, o fim do conhecimento através da informação e o fim da imaginação através da hiper-realidade" (Nunes, 1995, p.7). 
Deste ponto de vista, a maximização da hiper-realidade consumada pela internet pode ser vista como um manto que cobre toda a realidade ou também como um desafio a novos entendimentos do que é o indivíduo, a sua personalidade e o seu corpo e do que é a comunidade em que se insere (Nunes, 1995, p.11). Porque, embora ambicioso na forma como engloba os mais avançados desenvolvimentos das tecnologias de informação e comunicação - realidade virtual, mundos paralelos, supressão de tempo/espaço - o pensamento de Baudrillard não indica uma fase seguinte e deixa em aberto que a evolução se faça dentro deste quadro de análise. Ou seja, o mundo não fecha na hiper-realidade, mas pode desenvolver-se nela.

Há no entanto teóricos que fazem uma distinção importante entre o conceito de simulação da hiperrealidade de Baudrillard e a moderna realidade virtual com tecnologias de simulação: no primeiro caso estamos perante uma relação passiva e exterior entre o sujeito e o objecto da simulação, mesmo que mediada por um ecrã, enquanto no segundo o sujeito mergulha dentro da realidade virtual e, mais importante, pode interagir com ela usando sensores e elementos mecânicos extensores do seu corpo (Poster, 2001, p.135). E isso pode fazer toda a diferença.

Seja como for, Baudrillard vai muito mais longe no encontro com o mundo moderno da comunicação do que poderia parecer à primeira vista. As suas teses, holísticas e globalizantes como são, englobam uma explicação para a maior parte do que têm sido os desenvolvimentos mais recentes da internet e não são contraditadas por ela. Quando falamos de jogos de realidade virtual, de colaboração (e comunicação) em tempo real à distância e/ou de algo (aparentemente) tão simples como o Google Earth, para dar apenas três exemplos, é impossível não pensar que qualquer dessas coisas está contida nas teses de Baudrillard.

\section{Jurgen Habermas: A esfera pública renascida}

Jürgen Habermas é, dos três grandes teóricos da comunicação identificados neste trabalho, o único que ainda é vivo. Por isso é, de certa forma, aquele que está em melhores condições para ser ele próprio a confrontar as suas teses sobre a teoria da comunicação com a realidade actual da comunicação na era da internet. $\mathrm{E}$ - talvez por isso - é aquele em que essa confrontação está mais envolvida em polémica.

Tal como McLuhan e Baudrillard, as teorias da comunicação de Habermas são holísticas, no sentido em que enquadram os fenómenos da comunicação numa visão geral da sociedade, tanto do ponto de vista sincrónico (o seu funcionamento) como diacrónico (a sua evolução). Nesse sentido, Habermas desenvolveu a teoria da esfera pública e da aç̧ão comunicativa como meio de explicar não só a evolução e funcionamento da comunicação em sociedade, como também a forma como essa evolução e funcionamento condicionam o modo de organização política, económica e social. A teoria da esfera pública 
descreve um local ideal no qual as escolhas colectivas são operadas por via do debate racional entre indivíduos livres e conscientes e a teoria da acção comunicativa descreve a forma como os percursos discursivos dos vários agentes produzem as escolhas sociais, dentro da esfera pública ou fora dela. Embora seja um conceito ideal, para Habermas a esfera pública é também um conceito historicamente real e delimitado, com o seu apogeu entre o fim do Antigo Regime e o início da Revolução Industrial. Nesse período histórico, coincidindo com a emergência da burguesia como classe social dominante, Habermas aponta os cafés europeus onde se discutia literatura, filosofia e política como o local no qual os cidadão exerciam o controlo do governo da sociedade constrangidos apenas pela sua racionalidade e pela vontade de contribuir para as melhores soluções colectivas. Para Habermas, esses locais eram a aproximação mais perfeita do mundo moderno às características ideais da democracia grega (Habermas, 1991, p. 160-2) Nesse sentido, a esfera pública tem uma dupla função. Por um lado é o espaço privilegiado de discussão e formação da opinião pública, que Habermas sempre teve o cuidado de distinguir quer da opinião pública tal como anunciada por qualquer tipo de sondagens ou estudos de opinião, quer das "opiniões públicas" (no plural), por mais homogéneas que sejam, que se possam gerar entre grupos sociais de indivíduos com interesses semelhantes. Esta distinção é importante no contexto da confrontação quer com os estudos de opinião quer com os múltiplos fóruns da internet. Mas - para Habermas - a esfera pública não serve apenas para gerar uma "opinião pública". Ela serve também para - discursivamente - traduzir essa opinião pública em acção política colectiva, sancionando e dirigindo o poder político num contexto democrático. Ou seja, o livre debate de ideias - tal qual ele idealmente acontecia nos cafés europeus referidos por Habermas - não era um fim em si mesmo, mas sim um meio para agir sobre a sociedade, de onde resulta o conceito de "aç̧ão comunicativa" ("communicative action" nas traduções inglesas), que é central nas teses de Habermas (Habermas, 1987, p.113).

Por outro lado, a juntar aos conceitos de "esfera pública" e de "acção comunicativa", devemos igualmente recuperar o conceito de "lifeworld", tal como usado por Habermas. Sem uma tradução fácil, este conceito tem sido referido em português como "mundo vivido" ou "mundividência" ("mundivivência" seria mais correcto, se a Língua Portuguesa o permitisse...) e expressa a visão geral do mundo e a forma como ela contextualiza e ao mesmo tempo é contextualizada pelas aç̧ões comunicativas dos indivíduos na esfera pública (Habermas, 1987, p.119-120). Ou seja, no conceito de "lifeworld" estão integradas não apenas as experiências subjectivas dos indivíduos mas também as suas experiências sociais de relação com os outros indivíduos, que simultaneamente condicionam e são condicionadas pelo seu horizonte cognitivo, expresso através das suas competências linguísticas e outras. É esta "visão" e "vivência" do mundo que enforma as escolhas sociais dos agentes da esfera pública. 
Ora, na época em que os jornais eram eminentemente literários e panfletários e em que as motivações para a sua edição eram de luta e debate político em respeito pelos princípios da esfera pública (Habermas, 1974, p.53-3), essa mesma esfera pública atingiu, segundo Habermas, o seu apogeu. E foi precisamente a institucionalização do debate público trazida pelos estados constitucionais burgueses (Habermas, 1991, p.184) que tirou aos media a sua função política e socialmente engajada e Ihes atribuiu uma função comercial que viria a estar na base do funcionamento dos modernos mass media enquanto mediadores das escolhas políticas colectivas. Ou seja, os media continuaram a desempenhar uma função de mediação e debate na esfera pública, mas a sua natureza - e por arrasto a natureza desse debate e da própria esfera pública - alteraram-se radicalmente.

Hoje, tal como no tempo em que Habermas escreveu as suas obras mais importantes, os mass media servem como ponto de convergência dos interesses de determinados grupos socioprofissionais, de interesses económicos e de interesses políticos veiculados por partidos (Habermas, 1991, p.176). E, na confluência desses interesses, estabelece-se uma aparência de debate e consequente decisão colectiva, quase sempre com a espectacularização característica dos modernos mass media. Para Habermas, no entanto, esse debate - e portanto também a escolha colectiva - são ilusórios e surgem como um "substituto para a acção" (Habermas, 1991, p.164) (4). E, sobretudo, veiculam escolhas colectivas que não são o resultado da aç̧ão racional e desinteressada dos indivíduos, mas sim da prevalência desses interesses privados e particulares sobre o interesse colectivo. São por isso escolhas enviesadas e incapazes de dirigirem correctamente a sociedade.

Segundo Habermas, uma vez vocacionados para exploração económica, os jornais tornaram-se "veículos de interesses" (Habermas, 1991, p.185-2). Mas - para além disso - Habermas também considerou que os novos media da sua época - rádio, filme e televisão - eram substancialmente diferentes dos jornais, uma vez que com estes - por causa das características próprias da descodificação da letra impressa, o leitor tinha uma relação mais distanciada e reflexiva do que com os novos media, que por isso tinham um impacto mais penetrante (Habermas, 1991, p.172-3).

Quando surgiu a internet, muitos académicos procederam a extensões do seu pensamento (Reinhgold, 2000, pp. 301-303) e, perante a world wide web, olharam para muitas das suas características e potencialidades como um elemento de revitalização da esfera pública precisamente nos termos em que Habermas a tinha descrito na sua época áurea (Sustein, 2008, pp 90/91). O próprio Habermas ficou em silêncio sobre a matéria e só se pronunciou sobre ela em 2006, afirmando o seguinte:

"The Internet has certainly reactivated the grassroots of an egalitarian public of writers and readers. However, computer-mediated communication in the web can claim unequivocal democratic merits only for a special context: It can undermine the censorship of authoritarian 
regimes that try to control and repress public opinion. In the context of liberal regimes, the rise of millions of fragmented chat rooms across the world tend instead to lead to the fragmentation of large but politically focused mass audiences into a huge number of isolated issue publics. Within established national public spheres, the online debates of web users only promote political communication, when news groups crystallize around the focal points of the quality press, for example, national newspapers and political magazines." (Habermas, 2006, p.423)

Ou seja, Habermas vê alguma utilidade na internet como forma de contornar a censura em países com regimes políticos autoritários, mas não como forma de enriquecimento da esfera pública devido à fragmentação do discurso que ela induz. Essa fragmentação continua a impor como necessário o efeito unificador dos media, o que confere à esfera pública na era da internet características não substancialmente diferentes das anteriores, segundo Habermas. Para ele, os media têm como função "seleccionar e processar conteúdos politicamente relevantes e assim intervir tanto na formação das opiniões públicas como na distribuição de interesses influentes" (Habermas, 2006, p.419). Nessa medida, o que os media produzem - e Habermas considera necessário ao funcionamento do sistema - são decisões colectivas unificadas que, segundo ele, a fragmentação da internet não permite.

Na sequência desta intervenção, Howard Reinghold, que tinha usado abundantemente as teses de Habermas no seu importante livro "The Virtual Community", de 1993, disse que o teórico alemão "não entende um fenómeno que é central para a aplicação da sua teoria" (Reinhgold, 2007) e Axel Burns, outro auto-intitulado "habermasiano" afirmou que Habermas "não entende a internet" e que o pensador alemão tem "uma aversão a aceitar a internet como parte da esfera pública ou (mais importante) a modificar o modelo da esfera pública para a era da rede" (Burns, 2007). Ambas as referências vêm de Stuart Geiger (Geiger, 2009).

Um dos seguidores de Habermas que mais trabalho produziu sobre as possíveis adaptações das suas teses é nova era da internet foi Douglas Kellner. Em primeiro lugar, Kellner considera que muitas das críticas feitas à esfera pública de Habermas resultam do facto de ela ter sido concebida como um tipo ideal, com naturais contingências de materialização em cada caso concreto (Kellner, 2009, p. 7). Aliás, refere Kellner, o próprio Habermas a apresentou assim (Habermas, 1992, p.422). Segundo Kellner, "numa época de revolução tecnológica na qual novas tecnologias estão a penetrar e a transformar radicalmente todos os aspectos daquilo que Habermas discute como sistema e lifeworld", as categorias de análise originais não podem continuar a ser mantidas". (Kellner, 2009, p.14). Da mesma forma, Kellner acha que Habermas falha na percepção de como os movimentos sociais tiram partido dos novos meios de comunicação para se organizarem, se informarem e expandirem o campo de acção política (Kellner, 2009, p.17). No fundo o que 
acontece é que Habermas não considera os novos media como tal na esfera pública contemporânea porque deriva todo o seu modelo da comunicação e discussão face-a-face e não da interaç̧ão mediada pelos media e pela tecnologia (Kellner, 2009, p17-18). Por isso, para Kellner "(...) in the contemporary high-tech societies there is emerging a significant expansion and redefinition of the public sphere - as I am conceiving it, going beyond Habermas, to conceive of the public sphere as a site of information, discussion, contestation, political struggle, and organization that includes the broadcasting media and new cyberspaces as well as the face-to-face interactions of everyday life. These developments, connected primarily with multimedia and computer technologies, require a reformulation and expansion of the concept of the public sphere" (Kellner, 2009, p.18)

Para Kellner, os primeiros mass media, como a rádio e a televisão, e agora os computadores ligados em rede, produziram novas esferas públicas para informação, debate e participação, as quais contêm o potencial para revigorar a democracia e difundir novas ideias, mas também para manipular, controlar e intensificar as diferenças entre quem tem acesso às tecnologias e quem não tem (Kellner, 2009, p.18-19). Mais uma vez, para se perceber se as novas tecnologias de informação e comunicação têm um efeito positivo ou negativo na constituição e funcionamento da esfera pública, teremos que olhar para a maneira como essas tecnologias são apropriadas e domesticadas. Quem irá controlar os media e as nova tecnologias? Como irá ser feito o controlo dos media? Como irá ser feito o seu financiamento? Que tipos de conteúdos serão distribuídos? (Kellner, 2009, p.19). Num quadro de crescente diversificação das fontes de informação para lá dos media tradicionais - jornais, revistas, televisões, rádios - como funcionará a esfera pública? É por causa de questões como estas que Kellner conclui que as teses de Habermas são mais necessárias que nunca para enfrentar os desafios do novo milénio. Mas que teremos que ir muito mais além das suas posições originais para encontrar as respostas que procuramos.

\section{Conclusão}

Dos três grandes teóricos da comunicação aqui em análise, McLuhan seria provavelmente o único que não teria problemas em confrontar as suas teses com a internet tal como nós a conhecemos hoje em dia. Muito pelo contrário! E com razão, uma vez que muito do que foi a evolução tecnológica da internet desde a criação da world wide web é uma decorrência das tecnologias que McLuhan já conhecia no seu tempo e que ele identificou com precisão (a importância dada ao telégrafo - muitas vezes esquecido - é um bom exemplo). Mas o que McLuhan não conseguiu prever - e por isso também não foi capaz de integrar nas suas teses - foram as manifestações sociais da tecnologia. Na verdade, para McLuhan, essa foi sempre uma questão menos relevante face ao carácter impositivo que a técnica dos media tinha na sua construção 
teórica. E daí derivou talvez a falha mais importante do seu pensamento, que foi não ter identificado a arquitectura em rede que a comunicação na internet adoptou e que é ela própria resultado de várias contingências não, como explica Manuel Castells (Castells, 2001, pp.34-41). Em boa parte, as tecnologias de informação e comunicação evoluíram conforme Marshal McLuhan previra. Mas é a sua apropriação social que explica o seu desenvolvimento actual.

Pelo contrário, os outros dois pensadores aqui analisados - Habermas e Baudrillard - construíram antes de mais edifícios sociológicos, até bastante desligados das técnicas ou tecnologias de comunicação em concreto, mas muito habilitados a explicarem o funcionamento global da sociedade e o papel central que nesse funcionamento - em ambos os casos - tem o processo de comunicação.

Obviamente existe um elemento alienatório das massas que nos sugere alguma semelhança entre as formas como Habermas e Baudrillard viam o problema. Habermas achava que os media, ao deixarem-se "ocupar" por interesses particulares, não conseguiam instituir uma verdadeira esfera pública e encenavam um debate de ideias que não era verdadeiro; e Baudrillard achava que, pela sua própria ideologia, os media encenavam uma hiper-realidade que ocultava a própria realidade. Mas, não só chegavam lá de forma muito diferente, como - mais importante - seguiam em frente por caminhos ainda mais diversos. Para o pensador alemão, nas sociedades modernas a esfera pública regulada pelos media falhava o cumprimento da sua missão; para o pensador francês, ao contrário, a hiper-realidade, mais do que um falhanço, era a evolução lógica do sistema de comunicação (e significação) na sociedade. Aliás, o próprio Baudrillard afirma que não vê esta passividade e alienação como como algo que o deva tornar pessimista, mas antes "irónico $e$ antagonístico" (Baudrillard, 1998, p.208), ou seja, sublinhando o carácter dialéctico da sua abordagem, que é afinal a razão que o leva a não fechar totalmente a porta à possibilidade de uma "subversão do código dos media, de um discurso alternativo e de uma reciprocidade radical da troca simbólica" (Habermas, 1998, p.208). Essa fresta aberta na porta não se consegue encontrar em Habermas. Embora por escolha própria, pois, como vimos, alguns dos seus seguidores acham que as novas tecnologias de informação e comunicação trazidas pelo computador e a internet, com a apropriação e incorporação social que estão a ter, têm condições de revitalizar a esfera pública ideal de Habermas e com isso projectar as suas teses no futuro.

Por outro lado, tanto para Baudrillard como para McLuhan os media atingem na era contemporânea uma época de clímax. Mas enquanto McLuhan vê esse clímax como a consumação da utopia da "aldeia global", Baudrillard vê-o como um mundo desolado de comunicação irreal (Nunes, 1995, p.5). Aliás, o filósofo francês vê esse facto como a base para criação de um mundo fragmentado de experiências individuais que, afinal, não está assim tão longe da fragmentação da internet que leva Habermas a descartar o seu putativo papel na revitalização da "esfera pública". 
Em suma, se em McLuhan temos um optimista alimentado pelo determinismo tecnológico, em Habermas e Baudrillard temos provavelmente dois pessimistas de origem marxista, que sentem mais dificuldade em encaixar nas suas teses a internet e os novos modelos de comunicação da sociedade em rede ou fazem-no estabelecendo uma continuidade não relevante com o passado. Uma coisa é certa: qualquer destes pensadores deixou raízes profundas na análise da sociedade e dos media dentro dela que servirão certamente de base a muitos investigadores no futuro - sejam eles mais optimistas ou mais pessimistas para continuarem a estudar o fenómeno que eles procuraram explicar.

\section{BIBLIOGRAFIA}

\section{Sobre McLuhan}

Benedetti, Paul, \& deHart, Nancy. (1997). Forward through the Rearview Mirror: Reflections on and by Marshall McLuhan. Cambridge, MA: MIT Press

Carr, Nick (1 Novembro 2007) "McLuhan would blow hot and cool about today's internet", The Guardian. Retirado de http://www.guardian.co.uk/technology/2007/nov/01/comment.internet

Castells, Manuel (2009) "Communication Power", New York, Oxford University Press

Castells, Manuel (2001) "A Galáxia Internet - Reflexões sobre Internet, Negócio se Sociedade", Lisboa, Fundação Calouste Gulbenkian

Ciastellardi, Matteo; Almeida, Cristina Miranda de; Scolari, Carlos A. (Ed.) (2011) "McLuhan Galaxy Conference - Understanding media, today, Barcelona, may 23th-25th", Barcelona, Collection Sehen

De Kerckove, Derrick (1997), "The Skin of Culture: Investigating the New Electronic Reality", London, Kogan Page

Jenson, Klaus Bruhn (ed.) (2002) "A Handbook of Media and Communication Research: Qalitive and Quantitative Methodologies", London and New York, Routledge 
Kaplan, Nancy (1 Março 1995 "What Neil Postman has to say..." , Computer-Mediated Communication Magazine, Volume 2, Number 3,Page 34. Retirado de:

http://www.ibiblio.org/cmc/mag/1995/mar/hyper/npcontexts 119.html

Levinson, Paul (1999) "Digital McLuhan - a guide to the information millennium", London, Routledge

Marchessault, Janine (2005) "Marshal McLuhan", London, Sage Publications

McLuhan, Marshal (1962) "The Gutemberg Galaxy - the making of typographic man", Toronto, University of Toronto Press

McLuhan, Marshal (Março 1969) "The Playboy Interview - A candid conversation with the high priest of popcult ans metaphysician of media", Playboy. Retirado de: http://hannemyr.com/links/mcluhan/pb.html

McLuhan, Marshal (1964) "Understanding Media - the extensions of men", London and News York

Postman, Neil (2006) "Amusing Ourselves to Death: Public Discourse in the Age of Show Business", London, Penguin Books.

Postman, Neil (1992) "Technopoly: The Surrender of Culture to Technology", New York, Vintage Books

Rifkin, Jeremy (2009) "The Empatic Civilization - The race do global consciousness in a world in crisis", Cambridge, Polity

Silverstone, Roger (2003) "Media and Technology in the Everyday Life of European Societies: Final Deliverable - The European Media and Technology in Everyday Life, 2000-2003" Media@lse, London School of Economics and Political Science.

\section{Sobre Baudrillard}

Baudrillard, Jean (1981) "Para uma Crítica da Economia Política do Signo", Lisboa, Edições 70

Baudrillard, Jean (1988) "Selected Writings", edited by Poster, Mark, Stanford University Press, California. 
Nunes, Mark (1995) "Baudrillard in Cyperspace: Internet, Virtuality, and Postmodernity", publicado na revista "Style" n029, 1995, pp.314-327. Retirado de http://www.cyberkuhinja.com/kitchenmedialab/download/ck1/Baudrillard\%20in\%20Cyberspace.rtf

Poster, Mark (2001) "What's the Matter with the Internet?", University of Minnesota Press, Minneapolis.

Thibaut, Claude (1996, 6 Março) "Baudrillard on the New Tecnhnologies - an interview with Claude Thibaut (trad. Suzanne Falcone), in The European Graduate School. Retirado de: http://www.egs.edu/faculty/jeanbaudrillard/articles/baudrillard-on-the-new-technologies-an-interview-with-claude-thibaut/

Wardrip-Fruin, Noah e Montfort, Nick (2003) "the New Media Reader", The MIT Press, London, 2003.

\section{Sobre Habermas}

Burns, Axel (2007, 18 Fevereiro) "Habermas and/against the Internet", in http://snurb.info. Retirado dia 29 Novembro 2012, de http://snurb.info/node/621

Geiger, R.Stuart (2009, 22 Dezembro) "Does Habermas Understand the Internet? The Algorithmic Construction of the Blogo/Public Sphere", in Gnovis Journal, Volume X, Número I, Outono 2009, Georgetown University.

Habermas, Jürgen (1987) "The Theory of Communicative Action, vol.2 - Lifeworld and System: a critique of functionalist reason", Boston, Beacon Press

Habermas, Jürgen (1992) "Further Reflections on the Public Sphere, in Calhoun, Craig (ed.) "Habermas and the Public Sphere", pp. 421-461, 1992, Massachusetts, MIT

Habermas, Jürgen (Novembro 2006) "Political Communication in Media Society: Does Democracy Still Enjoy an Epistemic Dimension? The Impact of Normative Theory on Empirical Research", Communication Theory, Volume 16, n04, pp.411-426, International Communication Association. Retirado de: http://onlinelibrary.wiley.com/doi/10.1111/j.1468-2885.2006.00280.x/full 
Habermas, Jürgen (Outono 1974) "The Public Sphere: An Encyclopedia Article (1964)", New German Critique, n03, pp.49-55. Retirado de http://www.jstor.org/discover/10.2307/487737?uid=3738880\&uid=2\&uid=4\&sid=21101471386937

Habermas, Jürgen (1991) "The Structural Transformation of The Public Sphere: An Inquiry into a Category of Bourgeois Society", Cambridge, MIT Press

Jeffries, Stewart (30 Abril 2010) "A rare interview with Jürgen Habermas", Financial Times. Retirado de: http://www.ft.com/intl/cms/s/0/eda3bcd8-5327-11df-813e-00144feab49a.html

Kellner, Douglas (2009) "Habermas, the Public Sphere, and Democracy: a Critical Intervention". Retirado de: http://pages.gseis.ucla.edu/faculty/kellner/essays/habermaspublicspheredemocracy.pdf

Reinhgold, Howard (2000) "The Virtual Community: Homesteading on the Electronic Frontier", Cambridge, MIT Press.

Reinhgold, Howard (2007, 5 Novembro) "Habermas blows off question about the Internet and the Public Sphere", in www.smartmobs.com. Retirado dia 29 Novembro 2012 de

http://www.smartmobs.com/2007/11/05/habermas-blows-off-question-about-the-internet-and-the-publicsphere/

Sustein, Cass R. (2008) "Neither Hayek nor Habermas", in Public Choice, Volume 134, Numbers 1-2, pp. 87-95. Retirado daqui: http://www.springerlink.com/content/b8167107/4662147/ 